\title{
Welfare and Distribution Effects of Water Pricing Policies
}

\author{
Arjan Ruijs
}

Received: 31 August 2007 / Accepted: 20 July 2008 / Published online: 20 August 2008

(C) The Author(s) 2008. This article is published with open access at Springerlink.com

\begin{abstract}
In this paper, distribution and welfare effects of changes in block price systems are evaluated. A method is discussed to determine, for a Marshallian demand function, equivalent variation in case of a block price system. The method is applied to compare, for the Metropolitan Region of São Paulo, alternative pricing policies on the basis of their demand, welfare and distribution effects of changing water prices. Results show that there is a trade off between average welfare and income distribution. A pro-poor price system may result in lower average welfare than a flat price system, but in higher individual welfare for the poor. Moreover, there is a trade off between revenues for the water company and income distribution. Even though pro-poor price systems may not be as good for average welfare as flat price systems, their direct effects on poverty are important. Introducing pro-poor price systems, however, may have financial consequences for the water companies.
\end{abstract}

Keywords Water demand $\cdot$ Equivalent variation $\cdot$ Social welfare $\cdot$ Income distribution

\section{Introduction}

A basic principle in economics is that in order to get efficient prices, they have to reflect marginal costs. As a consequence, economic theory often recommends the application of flat prices. However, for some goods, such as residential water and electricity, block pricing systems are applied in many countries. Such pricing systems are said to be better for income distribution as, in case of progressive block price systems, poor households who consume less, pay lower average prices. A drawback of block pricing is, however, a potential welfare loss. Even though direct income transfers may lead to larger welfare increases for poor consumers than in-kind subsidies of the same amount, many (especially public) water suppliers employ block pricing systems as they not only try to promote efficiency

\footnotetext{
A. Ruijs ( $\square)$

Environmental Economics and Natural Resources Group, Wageningen University, P.O. Box 8130, 6700 EW Wageningen, The Netherlands

e-mail: arjan.ruijs@wur.nl
} 
but also have other objectives related to equity, cost recovery and local acceptability (Arbués and Villanúa 2006). Moreover, particularly in developing countries, alternative systems for improving social security, like transfers through income taxes, do not function properly. Comparisons between the welfare and distribution effects of alternative pricing systems are rare in the literature as the methods to derive the welfare effects are not straightforward. Next to that, as so many public utilities do apply or are thinking of applying block tariffs, getting more insights into the welfare and distributional effects of alternative pricing systems is necessary.

Therefore, the objective of this paper is to discuss how distribution and welfare effects of changes in block price systems can be analyzed. A method is discussed with which for a known, linear Marshallian demand function, equivalent variation of a change in the block price system can be determined. This method extends existing methods used for deriving equivalent variation on the basis of Marshallian demand curves so that they are applicable for block pricing systems. The method is used to compare for the Metropolitan Area of São Paulo alternative pricing policies on the basis of their water demand, distribution and welfare effects. It will especially be discussed whether the additional information obtained on individual equivalent variation and social welfare may affect the ranking of alternative price instruments. Note that a partial equilibrium approach is adopted and that indirect welfare effects of changes in pricing policies are not considered.

An extensive literature exists on welfare measurement (see e.g. Slesnick 1998 for an overview). The correct measure to use for determining welfare effects of price changes are Hicks' measures of Compensating Variation or Equivalent Variation. Most papers dealing with this issue concentrate on determining compensating or equivalent variation in case of a linear budget line. Those considering block price systems especially focus on effects of labor taxation (see e.g. Hausman 1980). A recent paper using a comparable, but slightly different methodology and price system is Reiss and White (2006), who estimate welfare effects of non-linear price systems for mobile phone services. They, however, concentrate on compensating variation, whereas it is argued in the current paper that equivalent variation should be applied if alternative price policies are ranked. Compensating variation may result in biased results. For the case of water, there is an extensive literature on the estimation of residential water demand functions (see e.g Arbués et al. 2003 for an overview). Moreover, there is a growing literature on the use of panel data methods to estimate demand under a block price system (see e.g. Hewitt and Hanemann 1995; Arbués and Villanúa 2006; Olmstead et al. 2007). Only few studies concentrate on the analysis of welfare effects of block price changes. Renzetti (1992) and García-Valiñas (2005) analyzed welfare effects of reforming water price systems, but they concentrated on the use of the optimal price theory using Ramsey prices which is not the focus of the current paper. Rietveld et al. (2000) for the case of Indonesia and Hajispyrou et al. (2002) for the case of Cyprus are two of the few studies focusing on the welfare effects of block price systems for residential water use. They, however, analyzed welfare effects of a price system changing from a block price into a flat price system. A novel element of the current paper is that especially the more complex case of changes within the block price system are analyzed in order to be able to assess the effects on both welfare and income distribution.

In this paper, in Sect. 2, a method is discussed to determine on the basis of the Marshallian demand function the equivalent variation and social welfare in case of a block price system. In Sect. 3, a linear water demand function is estimated for the Metropolitan Region of São Paulo which is used in Sect. 4 to analyze the welfare and distribution effects of changes in the price system. Finally, in Sect. 5 a number of conclusions are drawn. 


\section{Marshallian Demand and Equivalent Variation}

As stated above, the correct measure to use for determining welfare effects of price changes are Hicks' compensating or equivalent variation. Compensating Variation (CV) measures 'the amount the consumer would pay or would need to be paid to be just as well off after the price change as she was before the price change' (Hausman 1981, p. 662). Equivalent Variation (EV), on the other hand, measures the 'amount the consumer would be indifferent about accepting in lieu of the price change' (Mas-Colell et al. 1995, p. 82). CV is based on ex-ante utility and EV on ex-post utility. In applied economics, however, an often used measure for welfare changes is consumer surplus. It measures the consumer's willingness to pay for a price change on the basis of the Marshallian demand function instead of the Hicksian demand function. Use of the Marshallian demand function is much easier as it is directly observable in practice, and therefore can be estimated on the basis of observed demand data. A drawback, however, is that it does not compensate for income effects of price changes, which are taken into account in the Hicksian demand function. Consumer surplus equals compensating variation only under specific circumstances. Willig (1976) argued that in most cases the differences between both welfare measures are small and therefore use of consumer surplus is an appropriate approximation of welfare changes. Others, however, show that these differences may be substantial. Making a choice between both welfare measures, however, is not necessary as Hausman (1981) and Vartia (1983) showed that indirect utility and therefore compensating and equivalent variation can be determined on the basis of the Marshallian demand function. Both methods are based on linear budget constraints. In the case of kinked budget curves and especially in the case of non-convex budget curves, things change.

In this paper, the method developed by Hausman (1981) is extended in order to derive equivalent and compensating variation in a situation with a non-convex budget set. Such a situation often applies for example in labor markets (see e.g. Hausman 1985). Similar situations also apply for electricity and water markets where progressive block price systems are combined with a high first block price (or a fixed fee) to account for fixed cost. In this section, I first briefly discuss the concept of equivalent and compensating variation, which of the two concepts should be used for ranking alternative policies and how it can be derived on the basis of the Marshallian demand function. Secondly, this method is extended for a situation with a convex kinked budget curve. Thirdly, it is discussed how to deal with nonconvex budget sets. Finally, using some of the elements discussed before, a measure for social welfare is discussed that can be used to assess the social welfare effects of block price changes.

Consider a two-good situation in which the second good, which can be interpreted as an aggregate commodity, is the numeraire whose price is held constant. The price vector is defined as $\boldsymbol{p}=(p, 1)$. The price of the first commodity $p$ and income $y$ are normalized with respect to the price of the second commodity and both commodities are assumed to be separable. At price $\boldsymbol{p}_{\mathbf{0}}=\left(p_{0}, 1\right)$ and income level $y_{0}$, demand is equal to $\boldsymbol{x}_{\mathbf{0}}=\left(x_{0}, x_{0}^{\prime}\right)$ and utility to $u_{0}\left(\boldsymbol{x}_{\mathbf{0}}\right)$ (see Fig. 1). If the price of commodity 1 decreases to $p_{1}$, the budget line shifts outwards and becomes flatter. The equivalent income, the income the consumer would need to be as well off without as with the price decrease, is equal to $y_{e}$. Equivalent variation is defined as $y_{e}-y_{0}$. The compensating income, the income the consumer would need to be as well off with as without the price change, is equal to $y_{c}$. Compensating variation is defined as $y_{0}-y_{c}$. Both income measures are used as a money metric indirect utility function. In case of a price increase $\mathrm{EV}$ and $\mathrm{CV}$ are equal to the welfare loss, whereas they are the welfare gain in case of a price reduction. The expenditure function at a given level of utility $u_{0}$ and 

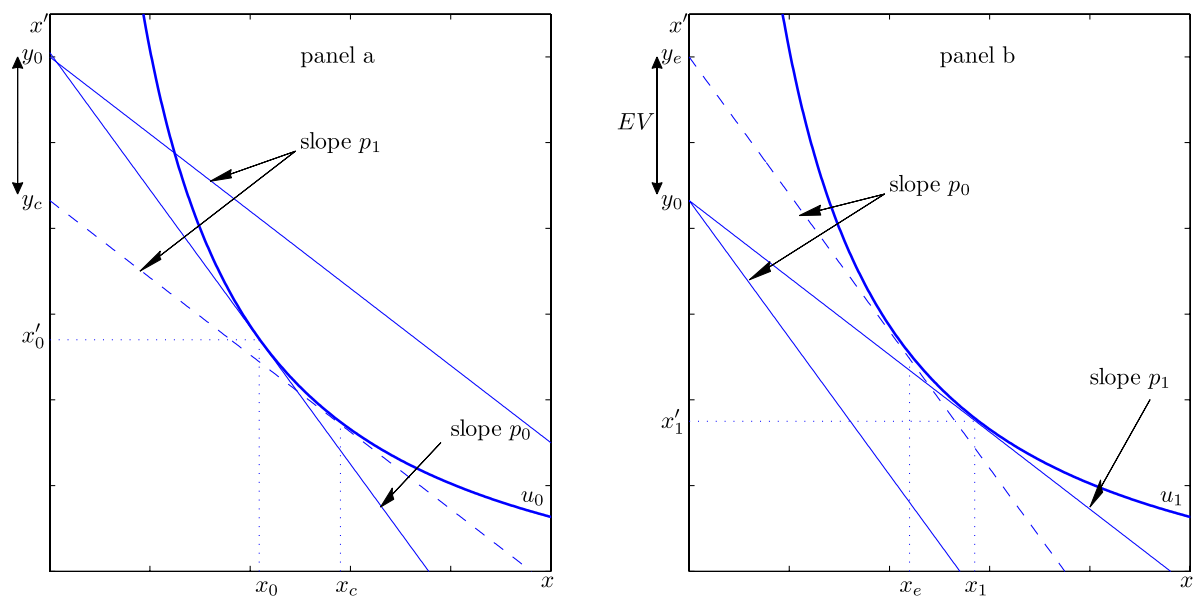

Fig. 1 Schematic representation of Compensating Variation (Panel a) and Equivalent Variation (Panel b)

price $\boldsymbol{p}=(p, 1)$ is defined as $e\left(p, u_{o}\right)=\min \boldsymbol{x}\left\{\boldsymbol{p} \cdot \boldsymbol{x} \mid u(\boldsymbol{x}) \geq u_{0}\right\} .{ }^{1}$ Using this, EV and $\mathrm{CV}$ of a price change from $p_{0}$ to $p_{1}$ are defined as

$$
\begin{aligned}
& E V\left(p_{0}, p_{1}, y_{0}\right)=e\left(p_{0}, u_{1}\right)-e\left(p_{1}, u_{1}\right)=e\left(p_{0}, u_{1}\right)-y_{0} \\
& C V\left(p_{0}, p_{1}, y_{0}\right)=e\left(p_{0}, u_{0}\right)-e\left(p_{1}, u_{0}\right)=y_{0}-e\left(p_{1}, u_{0}\right)
\end{aligned}
$$

The first question is which of the two measures to use. Chipman and Moore (1980) and Mas-Colell et al. (1995) showed that not CV, but only EV can be used for ranking alternative policies with different price vectors. The reason is that in $\mathrm{CV}$, the money metric indirect utility levels are based on new prices and initial utility, whereas in EV, they reflect the new utility levels that will be obtained with the new prices. ${ }^{2}$

The second question is how to derive from the Marshallian demand function the corresponding expenditure function. For a linear Marshallian demand function, Hausman (1981) showed that the expenditure function can be derived by using Roy's identity and the definition of the indirect utility function. Introduce a linear Marshallian demand function $x(p, y)=\alpha p+\beta y+\gamma z^{\prime}$ with coefficients $\alpha$ and $\beta$, row vector of coefficients $\gamma$, and the vector of other variables affecting demand $z$. Moreover, introduce the indirect utility function

$$
V(p, y)=\max \{u(\boldsymbol{x}) \mid \boldsymbol{p} \cdot \boldsymbol{x} \leq y\}
$$

\footnotetext{
1 For simplicity, in the definitions of the expenditure function $e\left(p, u_{0}\right)$, demand function $x(p, y)$, indirect utility function $V(p, y)$, equivalent variation $E V(\cdot)$ and compensating variation $C V(\cdot)$, only the price $p$ of the first commodity is mentioned as the price of the second commodity is held constant.

2 In case a price $p_{0}$ is compared with prices $p_{1}$ and $p_{2}$, the difference in equivalent variation between both prices is $E V\left(p_{0}, p_{1}, y_{0}\right)-E V\left(p_{0}, p_{2}, y_{0}\right)=e\left(p_{0}, u_{1}\right)-e\left(p_{0}, u_{2}\right)$ and the difference in compensating variation is $C V\left(p_{0}, p_{1}, y_{0}\right)-C V\left(p_{0}, p_{2}, y_{0}\right)=e\left(p_{2}, u_{0}\right)-e\left(p_{1}, u_{0}\right)$. Chipman and Moore (1980) proved that if income does not change if prices change and if preferences are homothetic, $C V\left(p_{0}, p_{1}, y_{0}\right)>$ $C V\left(p_{0}, p_{2}, y_{0}\right)$ if $p_{1}<p_{2}$ and $\mathrm{CV}$ will rank the different policies correctly. If this assumption does not apply, however, CV not necessarily ranks $p_{1}$ and $p_{2}$ correctly but EV will (see also Mas-Colell et al. 1995, p. 86). As will be discussed below, in the case analyzed in this paper income does change if the block price changes due to a change in implicit subsidy received by the consumers if prices change and therefore EV should be used to rank alternative policies.
} 
and Roy's identity according to which

$$
x(p, y)=-\frac{\partial V(p, y) / \partial p}{\partial V(p, y) / \partial y}
$$

For the linear demand function, (3) gives a differential equation for which Hausman (1981) proved that the indirect utility function $V(p, y)$ has the following form

$$
V(p, y)=\exp (-\beta p)\left[y+\frac{1}{\beta}\left(\alpha p+\frac{\alpha}{\beta}+\gamma z^{\prime}\right)\right]
$$

It can easily be shown that this function satisfies the integrability conditions as it is continuous, quasi-convex in $p$, homogeneous of degree zero in $p$ and $y$ and non increasing in $p$. Homogeneity of degree zero in $p$ and $y$ follows directly from the assumption that both $p$ and $y$ are deflated by the price of the other good which is by assumption equal to 1 . This proves that the linear demand function follows from a rational preference relation (Mas-Colell et al. 1995). ${ }^{3}$ By substituting in (4) income $y$ by expenditures $e(p, u)$ and $V(p, y)$ by $u$, the corresponding expenditure function follows

$$
e(p, u)=u \exp (\beta p)-\frac{1}{\beta}\left(\alpha p+\frac{\alpha}{\beta}+\gamma z^{\prime}\right)
$$

As a consequence, using (4) and (5), EV in (1) can easily be calculated if the Marshallian demand function is known.

Let us now turn to the question how to determine equivalent variation in case of a kinked budget curve. Consider for the moment for commodity 1 a two-tiered block price system with block prices $\boldsymbol{p}^{\boldsymbol{b}}=\left(p^{1}, p^{2}\right)$, with $p^{i}$ the price in block $i$ and in which price jumps from $p^{1}$ to $p^{2}$ if demand exceeds $\bar{x}$ (see Fig. 2). Assume for the moment a convex budget set with $p^{1} \leq p^{2}$. Note that still the price of the second commodity is equal to 1 , so that the price vector for the two commodities is $\boldsymbol{p}=\left(\boldsymbol{p}^{\boldsymbol{b}}, 1\right)$. For this situation, equivalent variation for a price change from $\boldsymbol{p}_{\mathbf{0}}^{\boldsymbol{b}}$ to $\boldsymbol{p}_{\mathbf{1}}^{\boldsymbol{b}}$ is, just as in (1), defined as

$$
E V\left(\boldsymbol{p}_{\mathbf{0}}^{\boldsymbol{b}}, \boldsymbol{p}_{\mathbf{1}}^{\boldsymbol{b}}, y_{0}\right)=e^{b}\left(\boldsymbol{p}_{\mathbf{0}}^{\boldsymbol{b}}, u_{1}\right)-y_{0}
$$

\footnotetext{
3 In this paper, a linear demand function is adopted. We make the assumption of implicit separability which justifies a demand curve with only one price (Arbués et al. 2004) and due to which the quasi indirect utility function (based only on the single good demand curve) can easily be derived and gives the same measure of equivalent variation as the actual, many good, indirect utility function (Hausman 1981). Regularly, linear demand functions are criticized as they would only apply for restrictive assumptions on the preference ordering. Given the assumptions made above, however, it is shown that in our situation this does not pose any problems (see e.g. Hausman 1981; LaFrance 1985; Arbués et al. 2004; Beattie and LaFrance 2006). Linear demand functions are also criticized as they imply a choke price for which demand is zero (Al-Qunaibet and Johnston 1985), which is inconsistent with water being a necessary good and due to which e.g. a log-log function may be more appropriate. On the other hand, linear demand also implies a satiation level at low prices, which is intuitively correct (Arbués et al. 2004) and which would not follow from a log-log demand function. In much of the empirical literature, functional forms are chosen that best fit the available data, without considering the underlying preference structures or related utility function. In the empirical analysis on water demand, the linear demand function is applied very often and for a study in Spain, Arbués and Villanúa (2006) show that the linear demand function is the most appropriate functional form. Next to that, also other forms are regularly adopted, like e.g. the log-log demand function which has the additional advantage that elasticities are fixed (Olmstead et al. 2007). However, there is no theoretical evidence that any of the functional forms would be best. Moreover, it can be argued that the demand function does not have to be linear over the full range of prices, as long as it is (approximately) linear over the range of prices considered. It is left for future research to find out how deriving Equivalent Variation in case of a kinded budget curve would change if other functional forms were chosen.
} 

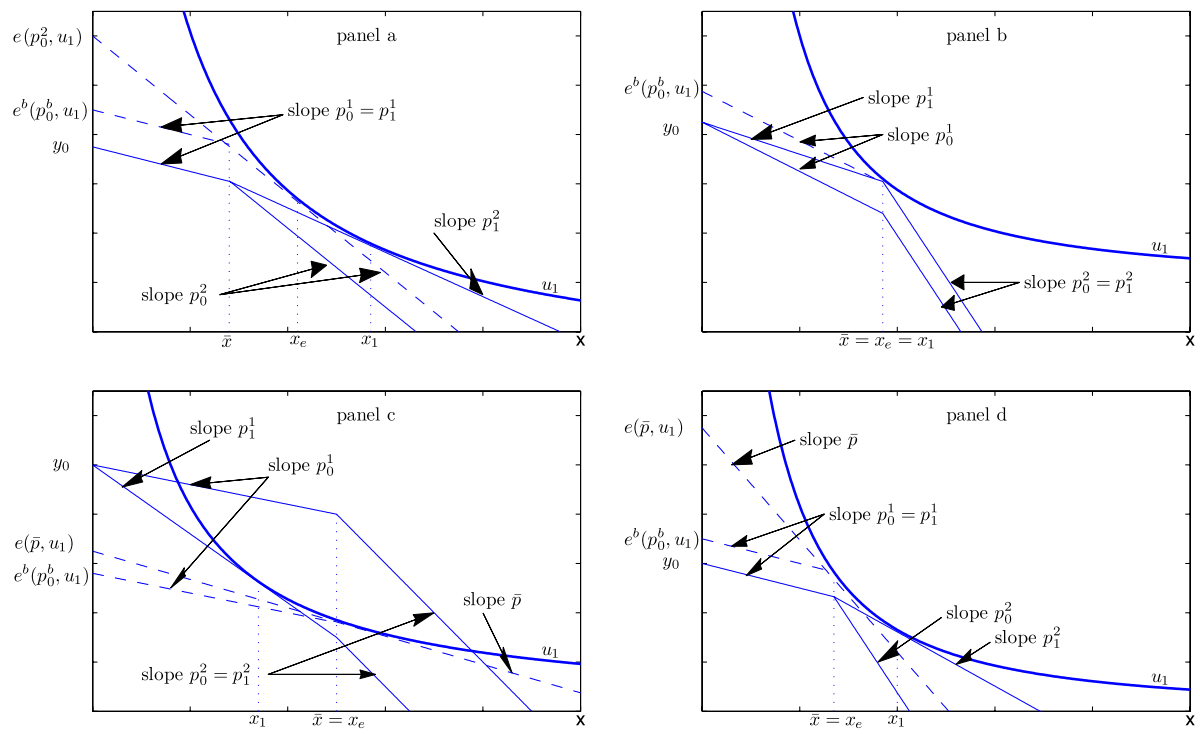

Fig. 2 Schematic representation of EV in case of a kinked budget curve. Expenditures in case of a kinked budget curve if $x_{e}$ and $x_{1}$ are at segment 2 of the budget curve (Panel a), $x_{e}$ and $x_{1}$ are at the kink (Panel b), $x_{e}$ is at the kink and $x_{1}$ at segment 1 of the budget curve (Panel c), and $x_{e}$ is at the kink and $x_{1}$ at segment 2 of the budget curve (Panel d)

with $e^{b}\left(\boldsymbol{p}_{\mathbf{0}}^{\boldsymbol{b}}, u_{1}\right)$ the expenditures in case of a block price system. These expenditures reflect the income needed to reach a utility level $u_{1}$ if the price vector is $\left(p_{0}^{b}, 1\right)$. Call $x_{e}$ the demand level at which there is tangency between the indifference curve $u_{1}=V\left(p_{1}^{b}, y_{0}\right)$ and the kinked budget curve characterised by prices $\left(\boldsymbol{p}_{\mathbf{0}}^{\boldsymbol{b}}, 1\right)$ and income $e^{b}\left(\boldsymbol{p}_{\mathbf{0}}^{\boldsymbol{b}}, u_{1}\right)$ (for an exact derivation of $u_{1}$, see the Appendix). The definition of $e^{b}\left(p_{0}^{b}, u_{1}\right)$ depends on the segment of the budget line on which $x_{e}$ is located. Three different cases can be distinguished: $x_{e}$ is at the first segment of the budget curve, at the second segment, or at the kink. Hausman (1985) proved that in case of a convex budget set and a quasi-concave utility function, there is a unique level of $x_{e}$, so that only one of the three cases will apply. First, consider the situation if $x_{e}$ is at the first segment of the budget curve. In that case, the situation is like in Panel (a) of Fig. 1 and the expenditures are like in (5) with $p$ substituted by $p_{0}^{1}$. In other words,

$$
e^{b}\left(\boldsymbol{p}_{\mathbf{0}}^{\boldsymbol{b}}, u_{1}\right)=e\left(p_{0}^{1}, u_{1}\right) \text { if } x\left(p_{0}^{1}, e\left(p_{0}^{1}, u_{1}\right)\right) \leq \bar{x}
$$

and in that case $E V\left(\boldsymbol{p}_{\mathbf{0}}^{\boldsymbol{b}}, \boldsymbol{p}_{\mathbf{1}}^{\boldsymbol{b}}, y_{0}\right)=e\left(p_{0}^{1}, u_{1}\right)-y_{0}$, see (6). Note that for this situation $x_{e}=x\left(p_{0}^{1}, e\left(p_{0}^{1}, u_{1}\right)\right)$.

Secondly, if $x_{e}$ is at the second segment, as in Panel (a) in Fig. 2, the expenditure function is different. In that case expenditures $e^{b}\left(\boldsymbol{p}_{\mathbf{0}}^{\boldsymbol{b}}, u_{1}\right)$ are not determined by substituting $p_{0}^{2}$ in (5), as an amount $\left(p_{0}^{2}-p_{0}^{1}\right) \bar{x}$ less is needed to purchase the quantity $x_{e}$. The expenditures $e\left(p_{0}^{2}, u_{1}\right)$, as determined by (5), are also called virtual expenditures. They are the expenditures necessary to purchase $x_{e}$ if the price were $p_{0}^{2}$ throughout and utility is $u_{1}$. Using this, for a block price system $\boldsymbol{p}_{\mathbf{0}}^{\boldsymbol{b}}=\left(p_{0}^{1}, p_{0}^{2}\right)$, expenditures to purchase $x_{e}$ are $e^{b}\left(\boldsymbol{p}_{\mathbf{0}}^{\boldsymbol{b}}, u_{1}\right)=e\left(p_{0}^{2}, u_{1}\right)-$ $\left(p_{0}^{2}-p_{0}^{1}\right) \bar{x}$. In this definition, $\left(p_{0}^{2}-p_{0}^{1}\right) \bar{x}$ is an implicit subsidy for consumers in block 2 . It is the difference between expenditures if $p_{0}^{2}$ were the price and the actual expenditures in 
the block price system. It follows that if prices change from $\boldsymbol{p}_{\mathbf{0}}^{\boldsymbol{b}}=\left(p_{0}^{1}, p_{0}^{2}\right)$ to $\boldsymbol{p}_{\mathbf{1}}^{\boldsymbol{b}}=\left(p_{1}^{1}, p_{1}^{2}\right)$, expenditures are equal to

$$
e^{b}\left(\boldsymbol{p}_{\mathbf{0}}^{\boldsymbol{b}}, u_{1}\right)=e\left(p_{0}^{2}, u_{1}\right)-\left(p_{0}^{2}-p_{0}^{1}\right) \bar{x} \quad \text { if } x\left(p_{0}^{2}, e\left(p_{0}^{2}, u_{1}\right)\right) \geq \bar{x}
$$

and in that case $E V\left(\boldsymbol{p}_{\mathbf{0}}^{\boldsymbol{b}}, \boldsymbol{p}_{\mathbf{1}}^{\boldsymbol{b}}, y_{0}\right)=e\left(p_{0}^{2}, u_{1}\right)-\left(p_{0}^{2}-p_{0}^{1}\right) \bar{x}-y_{0}$, see (6). ${ }^{4}$ For this case $x_{e}=x\left(p_{0}^{2}, e\left(p_{0}^{2}, u_{1}\right)\right)$. Note that a change from a flat to a block pricing system or from a block to a flat price system is a special case of the method discussed above in which for the flat price system $p^{1}=p^{2}$.

Thirdly, if $x_{e}$ is at the kink, $x_{e}=\bar{x}$, the situation is more complex (see Panel (b)(d) in Fig. 2). This situation happens if tangency with the indifference curve is at a point $x\left(p_{0}^{1}, e\left(p_{0}^{1}, u_{1}\right)\right)>\bar{x}$ for the budget line with slope $p_{0}^{1}$ and at a point $x\left(p_{0}^{2}, e\left(p_{0}^{2}, u_{1}\right)\right)<\bar{x}$ for the budget curve with slope $p_{0}^{2}$. The question is how to derive the price $\bar{p}$ and virtual income $\bar{y}=e\left(\bar{p}, u_{1}\right)$ for which preferred demand would be $\bar{x}$. How $\bar{p}$ and $e\left(\bar{p}, u_{1}\right)$ look like depends on whether the demand level after the price change, $x_{1}$, is at the kink or in one of the segments of the budget curve. If demand $x_{1}$ and $x_{e}$ are at the kink, the method is simple (see Panel (b) of Fig. 2). In that case, for demand for commodity 2, the numeraire, it has to hold that $\bar{x}^{\prime}=y_{0}-p_{1}^{1} \bar{x}=e^{b}\left(\boldsymbol{p}_{\mathbf{0}}^{\boldsymbol{b}}, u_{1}\right)-p_{0}^{1} \bar{x}$. It directly follows that $e^{b}\left(\boldsymbol{p}_{\mathbf{0}}^{\boldsymbol{b}}, u_{1}\right)=y_{0}+\left(p_{0}^{1}-p_{1}^{1}\right) \bar{x}$ and that equivalent variation is

$$
E V\left(\boldsymbol{p}_{\mathbf{0}}^{\boldsymbol{b}}, \boldsymbol{p}_{\mathbf{1}}^{\boldsymbol{b}}, y_{0}\right)=\left(p_{0}^{1}-p_{1}^{1}\right) \bar{x}
$$

If demand level $x_{1}$ is in block $i$ and demand level $x_{e}$ is at the kink (see Panel (c) and (d) in Fig. 2), the method is more complex. In that case, the virtual equivalent income $\bar{y}=e\left(\bar{p}, u_{1}\right)$ and price $\bar{p}$ for which demand would be $\bar{x}$ can be determined by using the demand functions $\bar{x}=\alpha \bar{p}+\beta \bar{y}+\gamma z^{\prime}$ and $x_{1}=\alpha p_{1}^{i}+\beta \tilde{y}_{0}^{i}+\gamma z^{\prime}$ and by the fact that it has to hold that $V\left(p_{1}^{i}, \tilde{y}_{0}^{i}\right)=V(\bar{p}, \bar{y})$, with $\tilde{y}_{0}^{1}=y_{0}$ if demand $x_{1}=x\left(p_{1}^{1}, y_{0}\right)$ is at segment 1 and $\tilde{y}_{0}^{2}=y_{0}+\left(p_{1}^{2}-p_{1}^{1}\right) \bar{x}$ if demand $x_{1}=x\left(p_{1}^{2}, y_{0}+\left(p_{1}^{2}-p_{1}^{1}\right) \bar{x}\right)$ is at segment 2 . Using the indirect utility function (4) it follows that for the linear demand function

$$
\begin{gathered}
\bar{p}=p_{1}^{i}+\frac{1}{\beta} \ln \left(\frac{\bar{x}+\frac{\alpha}{\beta}}{x_{1}+\frac{\alpha}{\beta}}\right) \\
e\left(\bar{p}, u_{1}\right)=\bar{y}=\frac{1}{\beta}\left(\bar{x}-\alpha \bar{p}-\gamma z^{\prime}\right)=\tilde{y}_{0}^{i}+\frac{1}{\beta}\left(\bar{x}-x_{1}\right)-\frac{\alpha}{\beta^{2}} \ln \left(\frac{\bar{x}+\frac{\alpha}{\beta}}{x_{1}+\frac{\alpha}{\beta}}\right) \\
e^{b}\left(p_{0}^{b}, u_{1}\right)=e\left(\bar{p}, u_{1}\right)-\left(\bar{p}-p_{0}^{1}\right) \bar{x}
\end{gathered}
$$

This gives an equivalent variation of

$$
E V\left(\boldsymbol{p}_{\mathbf{0}}^{\boldsymbol{b}}, \boldsymbol{p}_{\mathbf{1}}^{\boldsymbol{b}}, y_{0}\right)=\left(p_{0}^{1}-p_{1}^{1}\right) \bar{x}-\frac{1}{\beta}\left(\bar{x}+\frac{\alpha}{\beta}\right) \ln \left(\frac{\bar{x}+\frac{\alpha}{\beta}}{x_{1}+\frac{\alpha}{\beta}}\right)+\frac{1}{\beta}\left(\bar{x}-x_{1}\right)
$$

Note that (9) and (11) are the same if $x_{1}=\bar{x}$.

In case of an $n$-tiered block price system, the methods discussed above slightly differ. Assume a situation with $n$ block prices, $\boldsymbol{p}^{\boldsymbol{b}}=\left(p^{1}, \ldots, p^{n}\right)$ with block frontiers equal to $\overline{\boldsymbol{x}}=\left(\bar{x}^{0}, \ldots, \bar{x}^{n}\right)$, so that for $\bar{x}^{i-1}<x<\bar{x}^{i}$ the price is equal to $p^{i}$. Note that $\bar{x}^{0}=0$ and

\footnotetext{
${ }^{4}$ Note that due to the implicit subsidy if demand is in block 2, the demand function $x=\alpha p^{2}+\beta\left(y+\left(p^{2}-\right.\right.$ $\left.\left.p^{1}\right) \bar{x}\right)+\gamma z^{\prime}$ is equal to $x=(\alpha+\beta \bar{x}) p^{2}+\beta\left(y-p^{1} \bar{x}\right)+\gamma z^{\prime}$. As a result, the price elasticity of demand changes (see also Olmstead et al. 2007). As usually $\alpha<0$ and $\beta>0$, it is in theory possible that $\alpha+\beta \bar{x}>0$, meaning that, perversely, demand increases if the marginal price increases. In this case, the income effect of a move between two consumption blocks is larger than the price effect. In practice this is usually not a problem.
} 
$\bar{x}^{n}=\infty$. If demand is in block 1 , the usual definition of expenditures is used. If demand is in block $i>1$, equivalent variation for a change from $\boldsymbol{p}_{0}^{b}$ to $\boldsymbol{p}_{1}^{b}$ is defined as

$$
E V\left(\boldsymbol{p}_{\mathbf{0}}^{\boldsymbol{b}}, \boldsymbol{p}_{\mathbf{1}}^{\boldsymbol{b}}, y_{0}\right)=\left[e\left(p_{0}^{i}, u_{1}\right)-\sum_{j=1}^{i-1}\left(p_{0}^{j+1}-p_{0}^{j}\right) \bar{x}^{j}\right]-y_{0}
$$

If $x_{1}$ is at kink or segment $l$ and $x_{e}$ is at kink $i, x_{e}=\bar{x}^{i}$, equivalent variation is

$$
\begin{aligned}
E V\left(\boldsymbol{p}_{\mathbf{0}}^{\boldsymbol{b}}, \boldsymbol{p}_{\mathbf{1}}^{\boldsymbol{b}}, y_{0}\right)= & {\left[e\left(\bar{p}, u_{1}\right)-\left(\bar{p}-p_{0}^{i}\right) \bar{x}^{i}-\sum_{j=1}^{i-1}\left(p_{0}^{j+1}-p_{0}^{j}\right) \bar{x}^{j}\right]-y_{0} } \\
= & \left(p_{0}^{i}-p_{1}^{l}\right) \bar{x}^{i}-\sum_{j=1}^{i-1}\left(p_{0}^{j+1}-p_{0}^{j}\right) \bar{x}^{j}+\sum_{j=1}^{l-1}\left(p_{1}^{j+1}-p_{1}^{j}\right) \bar{x}^{j} \\
& -\frac{1}{\beta}\left(\bar{x}^{i}+\frac{\alpha}{\beta}\right) \ln \left(\frac{\bar{x}^{i}+\frac{\alpha}{\beta}}{x_{1}+\frac{\alpha}{\beta}}\right)+\frac{1}{\beta}\left(\bar{x}^{i}-x_{1}\right)
\end{aligned}
$$

The last term at the right-hand side of (12) and the last two terms at the right hand side of the first line of (13) are equal to the implicit subsidy the consumer receives. It is equal to the difference between what the consumer would pay if the only price were price $p_{0}^{i}$ or $\bar{p}$ and the expenditures in the block price system. In the water demand and electricity literature, this term is usually defined as the difference variable and is first introduced by Nordin (1976).

The final element to be discussed deals with how to determine the segment at which optimal utility is obtained in case of a non-convex budget set. This method is taken from Hausman (1985). In case of a convex budget curve the method is as discussed above. For each segment $i$ of the budget curve, it is determined what will be demand if the marginal price were block price $p^{i}$. Demand lies on segment $i$ if $\bar{x}^{i-1}<x\left(p^{i}, \tilde{y}^{i}\right) \leq \bar{x}^{i}$. In case of a convex budget set and a quasi concave utility function, this procedure results in the unique utility optimizing demand level (Hausman 1985). In the non-convex case, however, which applies for example in case of a (partly) regressive block price system, a unique optimum no longer necessarily exists as the indifference curves can be tangent to multiple segments of the budget curve. Information about the utility or indirect utility function has to be known to find the utility maximizing demand level. If this information is known, the non-convex budget set can be subdivided into a finite number of convex subsets, numbered $j=1, \ldots, J$. So, the set of segments $I=\{1, \ldots, n\}$ can be subdivided into $J$ subsets $I_{j}=\left\{i_{j-1}+1, \ldots, i_{j}\right\}$, with $i_{0}=0$ and $i_{j}=n$. For each convex subset $j$ and $i \epsilon I_{j}$, the optimal demand level $x_{j}\left(p^{i}, \tilde{y}^{i}\right)$, and corresponding price $p^{i}$ and indirect utility level $V_{j}\left(p^{i}, \tilde{y}^{i}\right)$ can be derived by using the method described above, in which virtual income $\tilde{y}^{i}=y_{0}+\sum_{j=1}^{i-1}\left(p^{j+1}-p^{j}\right) \bar{x}^{j}$. The overall optimal demand level can be determined by choosing the price $p^{i}$ and demand $x\left(p^{i}, \tilde{y}^{i}\right)$ corresponding to the segment yielding the highest indirect utility: $V^{*}=\max \left(V_{1}, \ldots, V_{j}\right)$. For the linear demand function, $V_{j}\left(p^{i}, \tilde{y}^{i}\right)$ is equal to (4).

For a given individual demand function, the measure of equivalent variation as discussed above gives the per capita welfare effects of price changes. This is very useful for evaluating distributional effects of price changes. It is, however, less suitable for ranking alternative price systems as that includes weighin tradeoffs between different income groups. For determining the overall impact of a price change, it is possible to follow a utilitarian social welfare approach and just aggregate the individual effects. However, in that case effects on the poor have the 
same weights as effects on the rich. An often applied measure that addresses the aggregation problem and takes into consideration inequality aversion is the Atkinson measure of social welfare. For given income levels $y_{k}, k=1, \ldots, K$, for each individual, social welfare is written as (see e.g. Atkinson 1970; Deaton 1997; Slesnick 1998)

$$
W=\frac{1}{K} \sum_{k=1}^{K} \frac{y_{k}^{1-\rho}}{1-\rho}
$$

with $\rho>0$ an indicator controlling for the degree of inequality aversion in which $\rho=0$ yields a utilitarian social welfare function and $\rho=\infty$ yields a Rawlsian maximin welfare function (Slesnick 1998). Usually for $\rho$ a value between 0 and 2 is chosen. ${ }^{5}$ Which value of $\rho$ should be adopted is a political question, which is not further discussed here. In this paper, it will only be assessed to what extent a different value of $\rho$ affects the ranking of alternative price systems.

To apply this measure for analyzing the social welfare effects of price changes, an income measure should be adopted that properly measures the income change that is equivalent to the welfare effect of a price change. For this, the measure of equivalent income is an appropriate measure. ${ }^{6}$ Equivalent income is the income that an individual would need before the price change (at price $\left.\boldsymbol{p}_{\mathbf{0}}^{\boldsymbol{b}}\right)$ to have the post-change utility level $\left(u\left(\boldsymbol{p}_{\mathbf{1}}^{\boldsymbol{b}}, y_{0}\right)\right)$, i.e. $y_{e}=e^{b}\left(\boldsymbol{p}_{\mathbf{0}}^{\boldsymbol{b}}, u_{1}\right)$ as defined in (7), (8) and (10). This gives the necessary ingredients to derive social welfare for a given value of inequality aversion $\rho$.

\section{Water Demand in the Metropolitan Region of São Paulo}

The Brazilian Metropolitan Region of São Paulo (MRSP) is one of the most densely populated areas in the world, housing more than 25 million people. The MRSP houses $50 \%$ of the state's population whereas it only occupies $2.7 \%$ of its territory. The MRSP regularly suffers from water shortage. As a result, SABESP, the main energy, water resources and sanitation secretary of the MRSP, has to ration water distribution. SABESP applies a five-tiered, nonconvex block price system in which between 1997 and 2002 the prices from block 2 to 5 were on average $p^{2}=0.41, p^{3}=1.43, p^{4}=2.04$ and $p^{5}=2.26 \mathrm{Real} / \mathrm{m}^{3}$ for consumption quantities ranging from 10-20, 20-30, 30-50 and higher than $50 \mathrm{~m}^{3}$ per month per connection, respectively. In that period, the price of the first $10 \mathrm{~m}^{3}$ was on average $p^{1}=2.56 \mathrm{Real} / \mathrm{m}^{3}$, which included the fixed costs. This system assures a safe minimum level of revenues for the water company, but may for the poorer population result in high average prices and relatively high expenses. Note that due to this price system, the budget constraint is non-convex. ${ }^{7}$ A connection contained on average 6.01 people. Comparable systems are applied in other Latin American cities (Walker et al. 2000).

\footnotetext{
5 Note that for $\rho>1$ social welfare levels $W$ become negative which can be prevented by a simple linear transformation.

6 Note that the measure of compensating income, as is used for determining CV $\left(y_{c}=e^{b}\left(\boldsymbol{p}_{\mathbf{1}}^{\boldsymbol{b}}, u_{0}\right)\right)$, is not an appropriate measure as it gives the income necessary to stay at the same utility level as before a price change from $p_{0}^{b}$ to $p_{1}^{b}$. The problem is that compensating income $y_{c}$ reduces if the price reduces whereas welfare increases in that case.

7 Note that for this case, the budget curve can easily be transformed into a convex budget curve. As the frontier of the first block is below subsistence level, all consumers will consume more than $10 \mathrm{~m}^{3}$ due to which the costs for the first block can be interpreted as a fixed charge and the unit cost for the first block are not relevant as marginal price. This results in a horizontal section in the budget line. As a result, the budget line is kinky but convex. This doesn't change anything to the method as discussed above or the results as presented below.
} 
In the past, much has been written about estimating water demand functions in a block price system (see e.g. Arbués et al. 2003 and Arbués and Villanúa 2006 for an overview). Even though using micro-level data is preferred for estimating water demand functions, only few papers actually use it due to the difficulty of obtaining these data (see e.g. Nieswiadomy and Molina 1989; Hewitt and Hanemann 1995; Arbués et al. 2004; Arbués and Villanúa 2006; Olmstead et al. 2007). With micro-data, the discrete/continuous choice model as proposed by Hewitt and Hanemann (1995) and Olmstead et al. (2007) could be applied, which specifically models the choice of consumption block, or a dynamic panel data method like in Arbués et al. (2004) and Arbués and Villanúa (2006). Similar to most papers focusing on water demand estimation, for the MRSP only aggregate data were available and, therefore, the estimates are based on these aggregate data. Besides a number of econometric estimation issues, demand functions can depend on average or on marginal prices, depending on how well consumers are informed about the block price system applied. According to Taylor (1975), price jumps caused by the movement to another block have an income effect due to which a demand function depending only on the marginal price is theoretically incorrect. For that reason, Nordin (1976) introduced a difference variable, accounting for the difference between the costs of water consumption if the marginal price were the only price and the true costs under the block price system. Its effect is hypothesized to be of the same magnitude as the income effect. Different empirical studies (see e.g. Billings and Agthe 1980; Chicoine and Ramamurthy 1986), however, have shown that the effect of a consumption related subsidy may be different from the income effect. This may be because consumers are not well informed, because the difference variable is small relative to income or because of estimation biases. A much cited comment on the use of marginal prices is that many people are not well informed and that therefore a demand model based on average prices is more realistic. To test for whether the marginal or average price model is superior, Opaluch $(1982,1984)$ proposed a model with a decomposed measure of average and marginal price. It is an empirical question which demand model is most appropriate.

For estimating a water demand function for the MRSP, aggregate data were used on monthly water consumption, number of connections, block prices and water rationing for the period July 1997-December 2002 obtained from SABESP for the consumers from 39 municipalities covering almost the entire MRSP (data were available for a period of 64 months). Prices were deflated using the Brazilian price index IPCA/IBGE, which is available on a monthly basis. Differences between minimum and maximum price observations are about $16 \%$ for $p_{2}, \ldots, p_{5}$ and $31 \%$ for the price of block 1 . In the data set, average consumption per household (total residential consumption divided by the number of connections) was always in the third consumption block. Although individual households may be in different consumption blocks, depending on income and other household variables, average consumption was in block 3 in all periods. Therefore, as only aggregate consumption data were available, $p_{3}$ is interpreted as the marginal price of household water consumption. Moreover, income data for the period 1996-2003 was obtained from the Brazilian Institute of Geography and Statistics (PNAD/IBGE) which were deflated using the Brazilian price index IPCA/IBGE, population data from the State Data Analysis System Foundation (SEADE) and monthly data on rainfall and temperature from the Institute of Atmosphere and Geography (IAG). For a more elaborate discussion of the data, see Ruijs et al. (2008).

Using these data, Ruijs et al. (2008) estimated the following marginal price, water demand function: $x_{t}=\alpha p_{t}+\beta y_{t}+\delta d_{t}+\gamma z_{t}{ }^{\prime}+\epsilon_{t}$, with $p_{t}, y_{t}$ and $d_{t}$ price in block $3\left(p^{3}\right)$, income and difference variable and $z_{t}$ a vector with rainfall, temperature, rationing, lagged consumption, lagged rainfall and the intercept and $\epsilon_{t}$ the error term. Using the approach of Opaluch (1982), it was estimated whether the marginal or average price model should be used, but based on 
the results neither of the methods could be rejected. Moreover, in this model, the coefficient $\delta$ of the difference variable was notably different from the income coefficient $\beta$, as observed in a number of other empirically estimated demand functions. In the current paper, a new function is estimated in which it is assumed that the income effect is equal to the effect of changes in the difference variable. As argued above, it is still under debate whether these effects should be similar or not. Even though some empirical studies show that the effects are different, allowing for differences in these coefficients is theoretically debatable and next to that, it would make the method discussed in Sect. 2 incorrect (see also Hausman 1981). After all, in that case it would have to be assumed that virtual income is not equal to income plus the difference variable, but smaller or larger, depending on the relation between $\beta$ and $\delta$. For that reason, the function estimated is

$$
x_{t}=\alpha p_{t}+\beta\left(y_{t}+d_{t}^{i}\right)+\mu x_{t-1}+\gamma z_{t}^{\prime}+\epsilon_{t}
$$

in which $d_{t}^{i}=\sum_{j=1}^{i-1}\left(p^{j+1}-p^{j}\right) \bar{x}^{j}$, see (12), if demand is in block $i$. Lagged consumption was included as it can be expected that people show a delay in the change of their behavior if prices change, especially if payments are made after consumption. The model was solved using OLS. As in the aggregate data all observations reflected consumption in the third consumption block, simultaneity which is caused by the endogenous relation between price and consumption in a block price system, was not a problem and it was not necessary to use instrumental variable techniques (see e.g. Arbués and Villanúa 2006). In the estimation, observations with studentized residuals exceeding \pm 2.8 were removed, leaving 63 of the 64 observations. Next to that, heteroscedasticity was tested for, normality of residuals was tested using the Kolmogorov-Smirnov test and for testing serial correlation the Durbin-H test was used. ${ }^{8}$ Results are presented in Table $1 .{ }^{9}$

The coefficient signs are as expected. Higher prices, more rainfall and more rationing lead to a reduced demand, whereas higher income and higher temperatures result in an increase of demand. Higher temperatures or less precipitation will induce people to take more showers, do the laundry more often, water the garden more often and use the swimming pool more often. Note that (15) can be interpreted as the short run demand function in which demand depends on the given demand from the previous period. Short run preferences depend upon policies and price levels from the past. In the longer run preferences may change due to changes in (price) policies. The long run demand function can be defined as

$$
x_{t}=\left(\alpha p_{t}+\beta\left(y_{t}+d_{t}^{i}\right)+\gamma z_{t}^{\prime}+\epsilon_{t}\right) /(1-\mu)
$$

In this specification it is assumed that price changes result in demand adjustments without any lags. Even though this is inconsistent with the empirical specification of partial adjustment, it

\footnotetext{
8 For testing serial correlation, the Durbin Watson test can not be used as it is biased towards 2 when a lagged variable is included. For that reason, the Durbin-H test was used. This test statistic is asymptotically distributed $\mathrm{N}(0,1)$ under the null hypothesis that there is no additional serial correlation. It can be closely approximated using the Durban Watson test statistic, using the following formula: $h=r \cdot(\sqrt{n /(1-n \cdot \operatorname{var}(\mu))})$ with $r \simeq 1-d / 2, d$ the Durbin Watson test statistic, $\operatorname{var}(\mu)=\left(\mu / t_{\mu}\right)^{2}, n$ the sample size and $t_{\mu}$ the $t$-ratio for coefficient $\mu$. For this case, $h=1.833$ which is not rejected at the 5 percent significance level (see e.g. Johnston 1984).

9 Next to the linear model, also a number of other functional forms were estimated, including a log-log demand function in which the logarithm of demand is a function of the logarithms of price and virtual income. The results of these estimates did not give any evidence why e.g the log-log model would be better than the linear model. As there is no theoretical evidence why a particular functional form should be adopted (see also Footnote 3), the linear function is used here. Adapting the method discussed in Sect. 2 for other functional forms is left for future research. Next to that, also additional linear models with more lagged variables were estimated. The estimated coefficients, however, were not significant.
} 
Table 1 Regression estimates of per capita water demand ( $\mathrm{m}^{3} / \mathrm{month} /$ person)

\begin{tabular}{|c|c|c|c|c|}
\hline & \multicolumn{2}{|c|}{ Descriptives } & \multicolumn{2}{|l|}{ Water demand } \\
\hline & Mean & Stand. Dev. & Coefficient & $\mathrm{t}$-Statistic \\
\hline Intercept & & & 2.2805 & $2.8114^{* *}$ \\
\hline Price $^{\mathrm{a}}$ & 1.43 & 0.05 & -0.5858 & $-1.7577^{*}$ \\
\hline Virtual income ${ }^{b}$ & 744.23 & 25.74 & 0.0011 & $2.2590^{* *}$ \\
\hline Time $^{\mathrm{c}}$ & & & -0.0040 & $-3.3694^{* *}$ \\
\hline Temperature $^{\mathrm{d}}$ & 19.55 & 2.57 & 0.0477 & $7.2488^{* *}$ \\
\hline Rainfall $^{\mathrm{e}}$ & 118.30 & 90.94 & -0.0004 & $-2.5994^{* *}$ \\
\hline Rationing $\mathrm{f}^{\mathrm{f}}$ & 0.26 & 0.44 & -0.0895 & $-3.1419^{* *}$ \\
\hline Lagged consumption ${ }^{\mathrm{g}}$ & & & 0.2928 & $3.3648^{* *}$ \\
\hline Adjusted $R^{2}$ & 0.820 & & Durbin-H test & 1.833 \\
\hline$F$-Statistic & 42.015 & & Kolmogorov-Smirnov Z & 0.815 \\
\hline Sample size & 63 & & & \\
\hline
\end{tabular}

Notes: ${ }^{*}$ Significant at $10 \%$ level, ${ }^{* *}$ Significant at $5 \%$ level, ${ }^{\mathrm{a}}$ Real $/ \mathrm{m}^{3},{ }^{\mathrm{b}}$ Real $/ \mathrm{month} /$ person, ${ }^{\mathrm{c}} \mathrm{Month},{ }^{\mathrm{d}}{ }^{\circ} \mathrm{C}$, ${ }^{\mathrm{e}} \mathrm{mm} / \mathrm{month},{ }^{\mathrm{f}} n=0$, yes $=1, \mathrm{~g}^{\mathrm{m}} / \mathrm{month} /$ person

is a convenient way of making demand independent from past policies and preferences (see e.g. LaFrance and de Gorter 1985). The price and income elasticities of demand, computed at the mean price and income values, are for the short run demand function equal to -0.20 and 0.19 , respectively, and for the long run demand function equal to -0.28 and 0.28 , respectively. Water demand is inelastic and elasticities are rather low but within the ranges mentioned in many other studies reporting price elasticities of demand ranging between -0.05 and -0.75 and income elasticities ranging between 0.05 and 0.50 with a few studies reporting elasticities exceeding 1 or even 2 (Dalhuisen and Nijkamp 2001; Arbués et al. 2003; Olmstead et al. 2007). As expected, long run demand elasticities are a bit less inelastic as consumers adjust their behavior to changing price and income levels.

\section{Scenario Analysis}

To illustrate the value of the additional information obtained with the method discussed above, the distribution and welfare effects of changes in block pricing systems in the MRSP on different income groups are analyzed, using the short and long run demand function estimated above (see 15 and 16). Demand changes, average prices, water bills, equivalent variation and social welfare are determined for a number of price systems for five income groups in order to explore the effects of price changes. Extrapolating the demand function to other income groups may result in biased estimates of real demand and welfare effects, especially for the poorest and richest income groups. The analysis could be more detailed if micro data were available. The analysis, however, will still give a good illustration of the method discussed above. Moreover, it will give a good indication of the importance of getting more information on income distribution effects of alternative price policies and the effects it has on the ranking of these alternatives. Due to the possible biases for the poorest and richest, however, the exact values of the results should be interpreted with care, even though it is not expected that the direction of change, the ranking of the price systems or the general observations made, will alter if more detailed data were available.

Using data on income distribution for the MRSP for the year 2000 (Minnesota Population Center 2006), average income is determined for five income quintiles, which is used to calculate their demand and average price (see Table 2). The average expenses on water as percentage of income are in line with data from the Brazilian Institute for Geography 
Table 2 Yearly per capita income, per capita demand, water bill and average price per income quintile for the short and long run demand functions

\begin{tabular}{|c|c|c|c|c|c|c|c|c|c|}
\hline \multirow[t]{2}{*}{$\begin{array}{l}\text { Income } \\
\text { quintile }^{\mathrm{a}}\end{array}$} & \multirow[t]{2}{*}{$\begin{array}{l}\text { Per capita } \\
\text { income } \\
\text { (Real/year) }\end{array}$} & \multicolumn{2}{|c|}{$\begin{array}{l}\text { Per capita } \\
\text { demand } \\
\left(\mathrm{m}^{3} / \text { year }\right)^{b}\end{array}$} & \multicolumn{2}{|c|}{$\begin{array}{l}\text { Water bill } \\
\text { (Real/year) }\end{array}$} & \multicolumn{2}{|c|}{$\begin{array}{l}\text { Average } \\
\text { price } \\
\left(\text { Real } / \mathrm{m}^{3}\right)^{\mathrm{c}}\end{array}$} & \multicolumn{2}{|c|}{$\begin{array}{l}\text { Water bill as } \\
\% \text { of income }\end{array}$} \\
\hline & & S.R. ${ }^{d}$ & L.R. ${ }^{\mathrm{d}}$ & S.R. & L.R. & S.R. & L.R. & S.R. & L.R. \\
\hline 1 & 1,257 & 42 & 40 & 63 & 60 & 1.48 & 1.48 & 4.98 & 4.75 \\
\hline 2 & 2,601 & 44 & 41 & 65 & 61 & 1.48 & 1.48 & 2.49 & 2.35 \\
\hline 3 & 4,361 & 46 & 44 & 68 & 64 & 1.48 & 1.48 & 1.55 & 1.48 \\
\hline 4 & 7,751 & 49 & 49 & 73 & 72 & 1.47 & 1.47 & 0.94 & 0.93 \\
\hline 5 & 28,753 & 68 & 75 & 105 & 120 & 1.54 & 1.59 & 0.37 & 0.42 \\
\hline Average & 8,945 & 50 & 50 & 75 & 75 & 1.49 & 1.51 & 0.83 & 0.84 \\
\hline
\end{tabular}

${ }^{a}$ Quintile 1 corresponds to the $20 \%$ of the population having the lowest income, Quintile 5 corresponds to the $20 \%$ of the population having the highest income. Income shares are $2.81 \%, 5.82 \%, 9.75 \%, 17.33 \%$ and 64.29\% for income Quintile 1, 2, 3, 4 and 5, respectively. Income shares are for 2000, Source: Minnesota Population Center (2006)

${ }^{\mathrm{b}}$ Consumers of Quintile 1, 2, 3 and 4 have a monthly consumption per connection in block 3. Consumers of Quintile 5 have a consumption in block 5

${ }^{c}$ Average price $=$ water bill/demand

${ }^{\mathrm{d}}$ S.R. = Based on short run demand function (15); L.R. = Based on long run demand function (16)

and Statistics (IBGE 2003), which report for the MRSP water expenses as part of total expenses to be on average $0.77 \%$. The differences between the poor and richer parts of the population, however, are considerable. Where the poorest $20 \%$ of the consumers spend on average almost $5 \%$ of their income on a consumption of $40-42 \mathrm{~m}^{3}$ per year, the richest part of the population spends only about $0.4 \%$ of their income on a consumption of $68-75 \mathrm{~m}^{3}$ per person per year. The richest consumers have a consumption in block 4 , whereas the others have their consumption in block 3 . The poorest population has a consumption in block 2 in some months. Average prices do not show a stepwise increase for the first four quintiles. So, although it is often claimed that a block price system is good for the poor, this can not be concluded for the current system in the MRSP which has a progressive price system only from the second till the fifth block and a very high price in the first block. Although average prices may show a slight progression, the water bill as a $\%$ of income for the poorest consumers is more than 14 times higher than for the richest consumers and still 5 times higher than for the consumers in the fourth income quintile. Comparing the short run and long run results shows that in the longer run the poorer population consumes less whereas the richer consume more. The price effect becomes stronger in the longer run but this is moderated slightly by the income effect. For the richest consumers, the income effect is stronger than the price effect, resulting in higher demand.

In a scenario analysis, it is investigated for two types of scenarios and using the long run demand function what will be the distributional effects of introducing alternative pricing mechanisms (see Tables 3 and 4). In the first scenario, a number of block price or block size changes are compared for which the welfare effects for the median consumer are negligible (i.e. for which $\mathrm{EV}=0$ for the consumers in block 3). In the second scenario, a number of block price changes are compared which are budget neutral for the water company, as results from the first scenario show that their revenues may change substantially. These scenarios correspond to policy guidelines regularly applied by policy makers if policy changes are proposed, and which will especially be important if public utilities are reorganized. Note that the exact levels of the policies depend, of course, on the exacts values of the model parameters, but that the types of policies discussed here are examples of policies that are 
regularly considered by decision makers. Remember that a partial equilibrium approach is adopted in which the indirect welfare effects of water suppliers' deficits or of changes in expenditures are not considered. An alternative and potentially interesting scenario would be the application of optimal nonlinear pricing (see e.g. Feldstein 1972; Renzetti 1992; Anderson 2004). As cost data necessary for this are not available, this aspect is kept for future research. ${ }^{10}$ The following scenarios are analyzed.

1. Block changes resulting in a zero welfare effect for the median consumer.

(a) Decrease $p^{1}$ with $15 \%$, increase $p^{2}$ and $p^{3}$ with $85 \%$ and do not change $p^{4}$ and $p^{5}$.

(b) Introduce a progressive block price system with $p^{1}=1, p^{2}=1.945, p^{3}=$ $2.60, p^{4}=3$ and $p^{5}=4 \mathrm{Real} / \mathrm{m}^{3}$.

(c) Introduce a flat price system with $p^{1}=p^{2}=p^{3}=p^{4}=p^{5}=1.481 \mathrm{Real} / \mathrm{m}^{3}$.

(d) Decrease $p^{1}$ with $15 \%$ only for the consumers of income Quintile 1, 2 and 3, increase $p^{2}$ and $p^{3}$ with $85 \%$ for all consumers and do not change $p^{4}$ and $p^{5}$.

(e) Keep the prices at their base level but change the block structure into $\bar{x}^{1}=$ $5.25, \bar{x}^{2}=10, \bar{x}^{3}=25$ and $\bar{x}^{4}=50 \mathrm{~m}^{3}$ per connection per month.

2. Block changes which are budget neutral for the water company.

(a) Decrease $p^{1}$ with $15 \%$, increase $p^{2}$ and $p^{3}$ with $84.6 \%$ and do not change $p^{4}$ and $p^{5}$.

(b) Introduce a progressive block price system with $p^{1}=1.36, p^{2}=1.945, p^{3}=$ $2.60, p^{4}=3$ and $p^{5}=4 \mathrm{Real} / \mathrm{m}^{3}$.

(c) Introduce a flat price system with $p^{1}=p^{2}=p^{3}=p^{4}=p^{5}=1.511 \mathrm{Real} / \mathrm{m}^{3}$.

(d) Decrease $p^{1}$ with $15 \%$ only for the consumers of income Quintile 1, 2 and 3, increase $p^{2}$ and $p^{3}$ with $58.77 \%$ for all consumers and do not change $p^{4}$ and $p^{5}$.

The results of the scenario analysis shows some interesting patterns even though welfare effects are, as expected, small. The reader is reminded that a positive value for the equivalent variation represents a welfare increase whereas a negative value represents a welfare decrease. Note, furthermore, that the pattern of the results as described below is similar if the short run demand function were applied. For all sub-scenarios of Scenario 1, the effect of the policy change results in a zero welfare effect for the consumers in Quintile 3. The changes in demand, average price, water bill and compensating variation differ substantially between the different income groups. For example, if in Scenario 1a the price of the first block is reduced by $15 \%$ and the second and third block price increase by $85 \%$, demand and water bills decrease, especially for the poor. On average, welfare slightly decreases ( -5.19 Real), but for the poor household welfare increases $(+0.52$ Real) whereas for the richest $40 \%$ of the population welfare decreases ( -3.43 and -23.53 Real, respectively). Moreover, in the results, for some quintiles, equivalent variation increases, whereas demand decreases, which seems to be counter intuitive. The main reason for the increase of EV is a reduction of the average price due to which a higher equivalent income is needed to reach with the ex-ante price system the ex-post utility level. The reason why demand decreases, even though the average price falls, is that for this scenario the marginal price for the consumers increases ( $p^{2}$ and $p^{3}$ increase) but that due to the reduction of $p^{1}$ the difference variable increases. The

10 It is recognized that many alternative scenarios of price change could be chosen. The scenarios chosen have as objective to explore whether the MRSP could adopt a price system that is more pro-poor without affecting to a too high extent total demand or total revenues for the water company. 
Table 3 Effects of changing block price structures on demand, average price, water bill and equivalent variation for different income groups and effects on revenues collected by the water company for Scenario 1

\begin{tabular}{|c|c|c|c|c|}
\hline Income quintile & $\begin{array}{l}\% \text { Change in } \\
\text { water demand }\end{array}$ & $\begin{array}{l}\text { Average } \\
\text { water price } \\
\left(\text { Real } / \mathrm{m}^{3}\right)\end{array}$ & $\begin{array}{l}\% \text { Change in } \\
\text { water bill }\end{array}$ & $\begin{array}{l}\text { Equivalent } \\
\text { variation } \\
\text { (Real) }\end{array}$ \\
\hline \multicolumn{5}{|c|}{ Scen. 1a: $p^{1}-15 \%, p^{2}$ and $p^{3}+85 \%$ and $p^{4}$ and $p^{5}+0 \%$} \\
\hline 1 & -0.7 & 1.47 & -1.9 & 0.52 \\
\hline 2 & -3.1 & 1.47 & -4.2 & 0.55 \\
\hline 3 & -8.4 & 1.47 & -9.2 & 0.00 \\
\hline 4 & -18.3 & 1.47 & -18.7 & -3.43 \\
\hline 5 & -0.1 & 1.90 & 19.6 & -23.53 \\
\hline Average & -5.7 & 1.61 & 0.08 & -5.19 \\
\hline \multicolumn{5}{|c|}{ Scen. $1 \mathrm{~b}: p^{1}=1, p^{2}=1.945, p^{3}=2.6, p^{4}=3$ and $p^{5}=4 \mathrm{Real} / \mathrm{m}^{3}$} \\
\hline 1 & -16.3 & 1.38 & -21.9 & 2.41 \\
\hline 2 & -13.2 & 1.42 & -17.1 & 1.34 \\
\hline 3 & -12.1 & 1.45 & -13.7 & 0.00 \\
\hline 4 & -18.3 & 1.47 & -18.4 & -3.66 \\
\hline 5 & -12.5 & 1.96 & 7.8 & -33.19 \\
\hline Average & -14.3 & 1.60 & -9.6 & -6.63 \\
\hline \multicolumn{5}{|c|}{ Scen. 1c: $p^{1}=p^{2}=p^{3}=p^{4}=p^{5}=1.481 \mathrm{Real} / \mathrm{m}^{3}$} \\
\hline 1 & -4.8 & 1.48 & -5.1 & 0.23 \\
\hline 2 & -2.1 & 1.48 & -2.3 & 0.13 \\
\hline 3 & -1.1 & 1.48 & -1.1 & 0.00 \\
\hline 4 & -1.0 & 1.48 & -0.6 & -0.27 \\
\hline 5 & 7.3 & 1.48 & 0.2 & 9.49 \\
\hline Average & 0.7 & 1.48 & -1.41 & 1.92 \\
\hline \multicolumn{5}{|c|}{ Scen. 1d: $p^{1}-15$ for Quintile 1,2 and $3 ; p^{2}$ and $p^{3}+85 \%$ and $p^{4}$ and $p^{5}+0 \%$ for all } \\
\hline 1 & -0.7 & 1.47 & -1.9 & 0.52 \\
\hline 2 & -3.1 & 1.47 & -4.23 & 0.55 \\
\hline 3 & -8.4 & 1.47 & -9.23 & 0.00 \\
\hline 4 & -18.3 & 1.66 & -8.09 & -11.09 \\
\hline 5 & -0.1 & 2.00 & 25.99 & -31.20 \\
\hline Average & -5.7 & 1.67 & 4.14 & -8.26 \\
\hline \multicolumn{5}{|c|}{ Scen. 1e: Block structure $\bar{x}^{1}=5.25, \bar{x}^{2}=10, \bar{x}^{3}=25, \bar{x}^{4}=50$} \\
\hline 1 & -3.6 & 1.49 & -3.5 & 0.00 \\
\hline 2 & -0.9 & 1.48 & -0.9 & 0.00 \\
\hline 3 & 0.0 & 1.48 & 0.0 & 0.00 \\
\hline 4 & -0.7 & 1.48 & -0.7 & 0.19 \\
\hline 5 & 0.0 & 1.67 & 5.1 & -6.10 \\
\hline Average & -0.9 & 1.54 & 0.8 & -1.18 \\
\hline
\end{tabular}

Entries in bold are the percentage change of the revenues collected by the water company. Percentage changes are compared with the base results as presented in Table 2

demand effect of an increase of the marginal price is much stronger than the income effect of an increase of the difference variable.

Next, if in Scenario 1b the price system is changed into a progressive block price system, the average welfare reduction is larger, especially so because of a larger negative welfare effect for the richest households. Moreover, welfare effects for the poorest are higher than in the other sub-scenarios. It is especially the larger reduction of the first block price which has a large effect on welfare for the poor as these fixed costs are such a large part of their water bill, especially compared to the situation for the richer groups. For this scenario, demand decreases as, like in Scenario 1a, the prices of the second till the fifth block increase. A positive effect is the large reduction of the water bill for the poorer consumers which is partly caused by a substantial reduction in demand. A drawback is, however, the reduction 
Table 4 Effects of changing block price structures on demand, average price, water bill and equivalent variation for different income groups and effects on revenues collected by the water company for Scenario 2

\begin{tabular}{lllll}
\hline Income quintile & $\begin{array}{l}\% \text { Change in } \\
\text { water demand }\end{array}$ & $\begin{array}{l}\text { Average } \\
\text { water price } \\
\left(\mathrm{Real} / \mathrm{m}^{3}\right)\end{array}$ & $\begin{array}{l}\% \text { Change in } \\
\text { water bill }\end{array}$ & $\begin{array}{l}\text { Equivalent } \\
\text { variation } \\
\text { (Real) }\end{array}$ \\
\hline
\end{tabular}

\begin{tabular}{|c|c|c|c|c|}
\hline \multicolumn{5}{|c|}{ Scen. $2 \mathrm{a}: p^{1}-15 \%, p^{2}$ and $p^{3}+84.58 \%$ and $p^{4}$ and $p^{5}+0 \%$} \\
\hline 1 & -0.7 & 1.47 & -1.9 & 0.56 \\
\hline 2 & -3.1 & 1.47 & -4.3 & 0.59 \\
\hline 3 & -8.4 & 1.47 & -9.3 & -0.04 \\
\hline 4 & -18.3 & 1.47 & -18.8 & -3.39 \\
\hline 5 & -0.1 & 1.90 & 19.5 & -23.38 \\
\hline Average & $-5.7 \%$ & 1.60 & 0.0 & -5.13 \\
\hline \multicolumn{5}{|c|}{ Scen. $2 \mathrm{~b}: p^{1}=1.365, p^{2}=1.945, p^{3}=2.6, p^{4}=3$ and $p^{5}=4 \mathrm{Real} / \mathrm{m}^{3}$} \\
\hline 1 & -16.3 & 1.60 & -9.8 & -4.86 \\
\hline 2 & -13.3 & 1.62 & -5.2 & -5.93 \\
\hline 3 & -12.1 & 1.64 & -2.5 & -7.34 \\
\hline 4 & -18.3 & 1.65 & -8.3 & -10.92 \\
\hline 5 & -12.6 & 2.07 & 13.9 & -40.45 \\
\hline Average & -14.3 & 1.77 & $\mathbf{0 . 0}$ & -13.90 \\
\hline \multicolumn{5}{|c|}{ Scen. 2c: $p^{1}=p^{2}=p^{3}=p^{4}=p^{5}=1.5112 \mathrm{Real} / \mathrm{m}^{3}$} \\
\hline 1 & -5.6 & 1.51 & -3.9 & -0.92 \\
\hline 2 & -2.8 & 1.51 & -1.0 & -1.08 \\
\hline 3 & -1.8 & 1.51 & 0.2 & -1.30 \\
\hline 4 & -1.6 & 1.51 & 0.8 & -1.72 \\
\hline 5 & 6.9 & 1.51 & 1.9 & 7.04 \\
\hline Average & 0.1 & 1.51 & 0.0 & 0.40 \\
\hline
\end{tabular}

Scen. 2d: $p^{1}-15$ for Quintile 1, 2 and 3; $p^{2}$ and $p^{3}+58.77 \%$ and $p^{4}$ and $p^{5}+10 \%$ for all

$\begin{array}{lrrrr}1 & -0.7 & 1.41 & -5.5 & 2.66 \\ 2 & -3.1 & 1.41 & -7.7 & 2.69 \\ 3 & -8.4 & 1.41 & -12.5 & 2.06 \\ 4 & -16.0 & 1.62 & -7.5 & -8.81 \\ 5 & -0.0 & 1.87 & 18.0 & -21.57 \\ \text { Average } & -5.2 & 1.60 & \mathbf{0 . 0} & -4.60\end{array}$

Entries in bold are the percentage change of the revenues collected by the water company. Percentage changes are compared with the base results as presented in Table 2

in revenues earned by the water company, which decreases by $9.6 \%$. This reduction may, especially, cause problems in the quality of the water services provided. For this scenario, average prices increase stepwise with income.

In contrast, the flat price system presented in Scenario 1c does result on average in a welfare increase, but especially so for the richer households. Effects on welfare for the poor are small. Even though demand slightly decreases for the poor, welfare slightly increases as average prices decrease.

In Scenario 1d, in which the price of the first block only decreases for the consumers from Quintile 1,2 and 3, on average welfare decreases. The welfare increases for consumers from the poorest three quintiles are small and, of course, similar to those of Scenario 1a. Effects are worse for consumers from Quintile 4 and 5. For this scenario, average prices for the different income groups show a stepwise increase and the poorest benefit somewhat, but at the expense of welfare for the richest consumers. The richest consumers, in fact, compensate the water company for the subsidies given to the poor. Such an income dependent price system is more favorable for the poor than for the rich. As the effects for the poor are so small, one can wonder whether such a system is politically feasible and whether the administrative costs are 
not exceeding the equity gains. Note that an income dependent reduction of the fixed costs, closely corresponds to an income transfer to the poorer consumers.

Finally, a change in the block structure as proposed in Scenario 1e, does not result in any significant changes for the poor. In order to keep the median consumer at the same utility level, the change in block sizes should be such that a reduction in expenses due to the decrease of $\bar{x}^{1}$, is compensated by an increase of expenses due to an increase of the size of block 3 (i.e. by reducing $\bar{x}^{2}$ ), in which consumption is located. As consumers of Quintile 1 to 3 are all in consumption block 3 , they are all affected in the same way. As a result also revenues from the water company will be almost unaffected. For consumers in Quintile 4 and 5, the welfare effect additionally depends on the change of the frontier of block $3\left(\bar{x}^{4}\right)$. If $\bar{x}^{4}$ decreases by a large enough quantity, demand for both groups will be in block 4 and EV will decline as a larger part of consumption will be consumed at a higher price. If the block frontier increases, the reverse will happen.

Summarizing, these results show that specifically considering the welfare effects for different income groups gives more insight in the effects of price changes than just considering the average welfare effects. The average effect of a price change may be positive, and therefore appealing to decision makers, but its individual effects for particular groups may be the opposite. Moreover, a system that treats consumers more equally (e.g. a flat price system) will result in general in higher average welfare whereas the more pro-poor systems are detrimental for average welfare. The results, however, show that the reverse is true for welfare effects for the poor. It should be noted that the welfare effects of the price changes proposed here are relatively small. The flat price system, which will result in the highest average welfare change, only has a marginal effect on welfare for the majority of the consumers compared to the benchmark, except for the rich. Note that a change from a progressive to a flat price system will have larger effects (the change from Scenario $1 \mathrm{~b}$ to $1 \mathrm{c}$ will result in an average welfare increase of 8.55 Real, but a reduction of welfare for the first two quintiles of 2.18 and 1.21 Real, respectively; welfare of the richest group will increase with 40.67 Real). Moreover, a drawback of the pro-poor price systems, is that revenues collected by the water company may decrease, which might endanger the financial viability of the water services provision and therefore have important indirect welfare effects. This might be prevented by introducing an income dependent system, but at the expense of the rich.

Next, Scenario 2 compares four different block price systems for which the effects on the revenues for the water company are negligible. Changing the block sizes without affecting the revenues is also possible, but will not be further considered here. Scenario $2 \mathrm{a}$ shows that a reduction of the first block price by $15 \%$ and an increase of the second and third block price by $84.6 \%$, will result in a welfare reduction $(-5.13$ Real) which is negative for the richer consumers and which is substantial for the richest quintile (-23.38 Real). Their water bill increases, whereas the bill for the poorer consumers decreases.

Scenario $2 \mathrm{~b}$ shows that welfare effects are worse for all consumers if a progressive price system is introduced. Compared to Scenario $1 \mathrm{~b}$, in order to reach budget neutrality, $p^{1}$ has to increase as well. Only increasing $p^{2}$ will not result in a budget neutral price change. This has a considerable effect on water demand and individual welfare for all consumers. It is an interesting observation that combining the objective of having a pro-poor price system with the objective of revenue neutrality for the water company is difficult even though the progressive price system is said to be pro-poor. In order to reach revenue neutrality $p^{2}$ and $p^{3}$ have to increase to such an extent that the positive welfare effects of decreasing $p^{1}$ are nullified.

The results of Scenario 2c show that even though average welfare increases, only the rich benefit from a budget neutral shift to a flat price system. Their welfare increases with 
7.04 Real. Welfare and demand for the poor decline. Finally, for the income dependent price system (Scenario 2d), a budget neutral price change results in a positive welfare effect for the poor. It has a negative average welfare effect $(-4.60$ Real $)$ and a negative effect on welfare for the rich $\left(-21.57\right.$ Real). The poor benefit $\left(+2.66\right.$ Real) as their fixed fees (price $\left.p^{1}\right)$ are reduced.

In summary, these results show that there is a trade off between a more equitable price system that is welfare increasing for the poor and revenues collected by the water company. Reaching both objectives with changes in the price system is difficult or even infeasible and alternative policies will be needed which can either be subsidizing the water company or financially supporting the poorer households through other price or income measures. Note that the results only give the partial equilibrium effects of price changes. A decrease in financial viability of the water company will negatively affect a welfare increase of individual consumers and a subsidy to either the water company or the poorer consumers has to be financed in one way or the other. Finally, changing the current price system into a flat price system which leaves the revenues for the water company unaffected results, like in Scenario 1, in a price system which on average is welfare improving but at the expense of the poor.

Finally, social welfare levels for the different scenarios are discussed. The Atkinson social welfare measure as discussed in (14) gives an aggregate welfare measure which takes into account inequality aversion. The higher inequality aversion, the more emphasis will be put on the welfare effects for the lower income groups. The results in Table 5 show, as can be expected, that the difference in social welfare between the different scenarios are small. Water expenses are on average about $0.83 \%$ of total income (see Table 2) and as a consequence, a small change in water prices only result in a small change in equivalent income. If no or little account is given to inequality (for $\rho=0$ and $\rho=0.5$ ), a flat price (Scenario 1c and 2c) gives the highest level of social welfare. This scenario is also the only scenario considered that results in a positive average equivalent variation. If more account is given to inequality, Scenario $1 \mathrm{~b}$ and $2 \mathrm{~d}$, become slightly better for social welfare. Even though average equivalent variation is negative and even though equivalent variation for the higher income groups does decrease, social welfare increases more than in the other scenarios. If no account is given to budget neutrality, the negative effects of an income dependent system (Scenario 1d) on the rich make that a progressive price system (Scenario $1 \mathrm{~b}$ ) scores better. If budget neutrality is considered, jointly with a reduction of the fixed fee, an income dependent system is more advantageous for the richer households. Due to the skewed income distribution in the MRSP,

Table 5 Percentage changes in social welfare for the different price scenarios for different levels of inequality aversion

\begin{tabular}{llllll}
\hline Scenario & $\rho=0(\%)$ & $\rho=0.5(\%)$ & $\rho=1(\%)$ & $\rho=1.5(\%)$ & $\rho=2(\%)$ \\
\hline Scen. 1a & -0.058 & -0.019 & -0.0015 & 0.0036 & 0.021 \\
Scen. 1b & -0.074 & -0.018 & $\mathbf{0 . 0 0 1 8}$ & $\mathbf{0 . 0 3 2}$ & $\mathbf{0 . 1 0}$ \\
Scen. 1c & $\mathbf{0 . 0 2 1}$ & $\mathbf{0 . 0 0 7 5}$ & 0.0012 & 0.0048 & 0.011 \\
Scen. 1d & -0.092 & -0.035 & -0.0045 & -0.0044 & 0.012 \\
Scen. 1e & -0.013 & -0.0041 & -0.00044 & -0.00061 & -0.00028 \\
Scen. 2a & -0.057 & -0.018 & -0.0014 & 0.0044 & 0.022 \\
Scen. 2b & -0.16 & -0.089 & -0.025 & -0.13 & -0.29 \\
Scen. 2c & $\mathbf{0 . 0 0 4 5}$ & $-\mathbf{0 . 0 0 5 5}$ & -0.0033 & -0.021 & -0.053 \\
Scen. 2d & -0.051 & -0.0084 & $\mathbf{0 . 0 0 4 1}$ & $\mathbf{0 . 0 4 3}$ & $\mathbf{0 . 1 3}$ \\
\hline
\end{tabular}

Percentage changes are compared to the base level of social welfare. Figures in bold give the subscenarios yielding the highest level of social welfare 
already for low levels of $\rho$, the more pro-poor price systems give a higher level of social welfare than the flat price system. The social welfare indicator confirms the results already given above that there is a trade off between income distribution and welfare. The more account is given to inequality, the more pro-poor pricing schemes should be. Due to the very small differences in social welfare between the different scenarios, however, a final choice on the optimal price system needs a more in depth analysis of the transaction costs of the different systems and of the indirect welfare effects of cross subsidization through pricing systems and requires a political choice on inequality aversion.

\section{Conclusions}

In this paper, the welfare and distribution effects of changes in block price systems are evaluated. A methodology is discussed with which equivalent variation can be determined in case of a block price system for a linear demand function. Due to the increasing attention paid to the need for water pricing and the effects of this on the poor, more insights in the individual and aggregate welfare effects of these changes are necessary. This paper shows that determining the exact welfare effects of changes in block price systems with equivalent variation is possible on the basis of the Marshallian demand function and that it is not much more difficult than determining the less exact measure of consumer surplus.

The methodology has been applied to evaluate welfare and distribution effects of residential water demand in the Metropolitan Region of São Paulo. Currently, the main water company in the MRSP applies a five-tiered block price system in which the prices in the second till the fifth blocks increase stepwise and in which the price in the first consumption block is higher than the price in the fifth block. Using aggregate, monthly data on consumption, prices, income, rainfall, temperature, rationing and population for the period July 1997 to December 2002, a linear demand function has been estimated. Price and income elasticities for the short run demand function are -0.20 and 0.19 , respectively, and for the long run demand function -0.28 and 0.28 , respectively. The inelasticity shows that it is difficult to reach a substantial reduction of demand, especially for the richer consumers and even in the longer run, by using only pricing policies. Additional policies will be needed to make people more aware of the water scarcity problems in urban areas.

Using the demand function, the effects of a number of scenarios of alternative price systems are evaluated for five income groups. The results show that although the average water price for the richer households is higher than for the poorer, water bills for the poor are a substantial part of their income whereas they are very small for the rich. The scenario analysis shows that, as can be expected, a flat price system is better for the rich and a progressive block price system is in general better for the poor. Moreover, if no account is given to inequality, social welfare is highest in a flat price system. If inequality aversion increases, pro-poor systems and income dependent systems, result in higher social welfare. The individual welfare effects, however, are only marginal. As a result no major income distribution changes can be reached in the MRSP if the water pricing system would be turned into a more pro-poor system. Furthermore, one can question whether the transaction costs of the administrative system necessary for an income dependent or pro-poor price system do not outweigh the welfare gains. An additional analysis of these transaction costs would be required for answering this question. Finally, there is a trade off between the financial situation of the water company and a more equitable price system that is welfare increasing for the poor. Compared to the current price system, a progressive block price system that does not affect the revenues collected by the water company, results in a welfare loss for all. 
Although price systems that consider income distribution may not be as good for average welfare as flat price systems, their direct effects on poverty and social welfare should not be neglected and are worthwhile to look at. The information obtained with the method discussed here is valuable for making deliberate choices on the most appropriate pricing policies and gives policy makers important information they would not have if only demand functions were known. As for the MRSP these effects turned out to be small, it can be questioned whether it would not be better and cheaper to use other instruments than water price changes to reach a situation in which consumption by the rich is treated differently than consumption by the poor.

Acknowledgements I would like to thank Hans Peter Weikard, Marrit van den Berg, Roel Jongeneel and two anonymous referees for their valuable comments and suggestions.

Open Access This article is distributed under the terms of the Creative Commons Attribution Noncommercial License which permits any noncommercial use, distribution, and reproduction in any medium, provided the original author(s) and source are credited.

\section{Appendix: Derivation of Utility Level $u_{1}$}

The definition of indirect utility shows that in case of a flat price $p$ and budget $y$, utility is equal to $u=V(p, y)$, see (4). In case of a kinked budget curve, the exact definition depends on the segment on which demand $x_{e}$ is located, see also Figs. 1-3, and see also the discussion on $e^{b}\left(\boldsymbol{p}^{\boldsymbol{b}}, u_{1}\right)$.

From this it follows that:

- if $x_{e}=x\left(p_{1}^{1}, y_{0}\right)<\bar{x}$, then $u_{1}=V\left(p_{1}^{1}, y_{0}\right)$

- if $x_{e}=x\left(p_{1}^{2}, y_{0}+\left(p_{1}^{2}-p_{1}^{1}\right) \bar{x}\right)>\bar{x}$, then $u_{1}=V\left(p_{1}^{2}, y_{0}+\left(p_{1}^{2}-p_{1}^{1}\right) \bar{x}\right)$

- else $x_{e}$ is at the kink $\left(x_{e}=\bar{x}\right)$ and it can easily be seen that in case of a convex budget curve $u_{1}<V\left(p_{1}^{1}, y_{0}\right)$ and $u_{1}<V\left(p_{1}^{2}, y_{0}+\left(p_{1}^{2}-p_{1}^{1}\right) \bar{x}\right)$. It can easily be seen from Fig. 3 that $u_{1}=\min _{\bar{p}}\left\{V\left(\bar{p}, y_{0}+\left(\bar{p}-p_{1}^{1}\right) \bar{x}\right) \mid p_{1}^{1} \leq \bar{p} \leq p_{1}^{2}\right\}$. From (2) follows that $\frac{\partial^{2} V}{\partial \bar{p}^{2}}>$

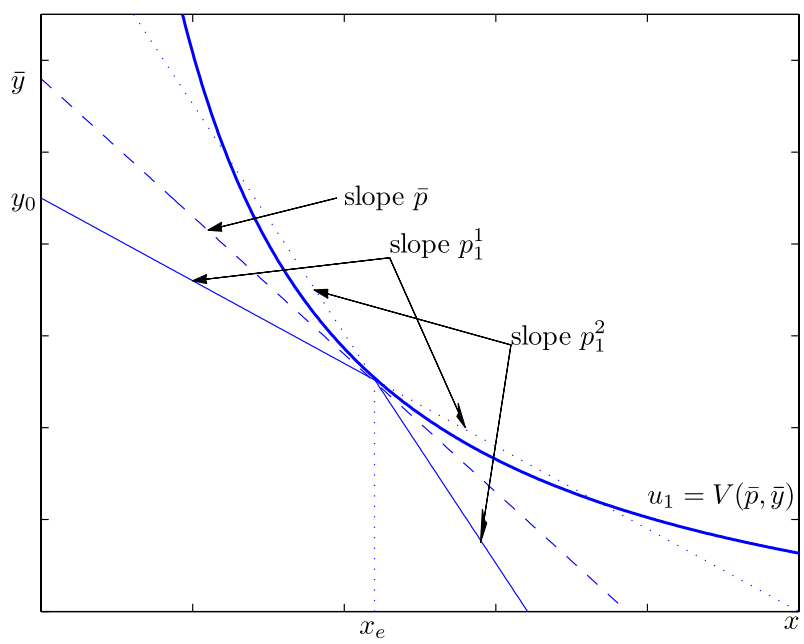

Fig. 3 Schematic representation of utility if demand $x_{1}$ is at the kink of the budget curve 
0 and $\frac{\partial V}{\partial \bar{p}}=0$ for $\bar{p}=\left[\bar{x}-\beta y_{0}-\gamma z+\beta p_{1}^{1} \bar{x}\right] /(\beta \bar{x}+\alpha)$. As $y_{0}-p_{1}^{1} \bar{x}=\bar{y}-\bar{p} \bar{x}$, it follows that $\bar{y}=y_{0}+\left(\bar{p}-p_{1}^{1}\right) \bar{x}$, which gives all ingredients to derive $u_{1}=V(\bar{p}, \bar{y})$.

\section{References}

Al-Qunaibet M, Johnston R (1985) Municipal demand for water in Kuwait: methodological issues and empirical results. Water Resour Res 21:433-438

Anderson T (2004) Essays on nonlinear pricing and welfare. PhD Thesis, Department of Economics, Lund University, Sweden

Arbués F, Villanúa I (2006) Potential for pricing policies in water resource management: estimation of urban residential water demand in Zaragoza, Spain. Urban Stud 43:2421-2442

Arbués F, García-Valiñas M, Martínez-Espiñeira R (2003) Estimation of residential water demand: a stateof-the-art review. J Socio-Econ 32:81-102

Arbués F, Barberán R, Villanúa I (2004) Price impact on urban residential water demand: a dynamic panel data approach. Water Resour Res 40, W11402

Atkinson AB (1970) On the measurement of inequality. J Econ Theory 2:244-263

Beattie B, LaFrance J (2006) The law of demand versus diminishing marginal utility. Rev Agric Econ 28:263-271

Billings R, Agthe D (1980) Price elasticities for water: a case of increasing block rates. Land Econ 56:73-84

Chicoine D, Ramamurthy G (1986) Evidence on the specification of price in the study of domestic water demand. Land Econ 79:292-308

Chipman J, Moore J (1980) Compensating variation, consumer's surplus, and welfare. Am Econ Rev 70:933-949

Dalhuisen J, Nijkamp P (2001) Critical factors for achieving multiple goals with water tariff systems. Tech. Rep. Tinbergen Institute Discussion paper TI2001-121/3, VU

Deaton A (1997) The analysis of household surveys: a microeconometric approach to development policy. Johns Hopkins University Press, Baltimore

Feldstein M (1972) Equity and efficiency in public sector pricing: the optimal two-part tariff. Q J Econ 86:175-187

García-Valiñas M (2005) Efficiency and equity in natural resource pricing: a proposal for urban water distribution services. Environ Resour Econ 32(3):183-204

Hajispyrou S, Koundouri P, Bashardes P (2002) Household demand and welfare: implications of water pricing in cyprus. Environ Dev Econ 7:659-685

Hausman J (1980) The effect of wages, taxes and fixed costs on women's labor force participation. J Public Econ 14(2):161-194

Hausman J (1981) Exact consumer's surplus and deadweight loss. Am Econ Rev 71(4):662-676

Hausman J (1985) The econometrics of non-linear budget sets. Econometrica 53(6):1255-1282

Hewitt J, Hanemann W (1995) A discrete/continuous choice approach to residential water demand under block rate pricing. Land Econ 57:173-192

IBGE (2003) Pesquisa de orcamentos familiares 2002-2003. IBGE, Brasil

Johnston J (1984) Econometric methods. McGraw-Hill, Singapore

LaFrance J (1985) Linear demand functions in theory and practice. J Econ Theory 37:147-166

LaFrance J, Gorter Hde (1985) Regulation in a dynamic market: the us dairy industry. Am J Agric Econ 67:821-832

Mas-Colell A, Whinston M, Green J (1995) Microeconomic theory. Oxford University Press, Oxford

Minnesota Population Center (2006) Integrated public use microdata series-international: Version 2.0. Tech. Rep., University of Minnesota, Minneapolis

Nieswiadomy M, Molina D (1989) Comparing residential water demand estimates under decreasing and increasing block rates using household data. Land Econ 65:280-289

Nordin J (1976) A proposed modification of taylor's demand analysis: comment. Bell J Econ 7(2):719-721

Olmstead S, Hanemann W, Stavins R (2007) Water demand under alternative price structures. J Environ Econ Manage 54:181-198

Opaluch J (1982) Urban residential demand for water in the United States: further discussion. Land Econ 58:225-227

Opaluch J (1984) A test of consumer demand response to water prices: reply. Land Econ 60:417-421

Reiss P, White M (2006) Evaluating welfare with nonlinear price. Tech. Rep., NBER Working Paper W12370

Renzetti S (1992) Evaluating the welfare effects of reforming municipal water prices. J Environ Econ Manage 22:147-163 
Rietveld P, Rouwendal J, Zwart B (2000) Block rate pricing of water in Indonesia: an analysis of welfare effects. Bull Indonesian Econ Stud 36(3):73-92

Ruijs A, Zimmermann A, van den Berg M (2008) Demand and equity effects of water pricing policies. Ecol Econ 66:506-516

Slesnick D (1998) Empirical approaches to the measurement of welfare. J Econ Lit 36(4):2108-2165

Taylor L (1975) The demand for electricity: a survey. Bell J Econ 6(1):74-110

Vartia Y (1983) Efficient methods of measuring welfare change and compensated income in terms of ordinary demand functions. Econometrica 51(1):79-98

Walker I, Ordoñez P, Serrano P, Halpern J (2000) Pricing, subsidies and the poor. Tech. Rep., Policy Research Working Paper No. 2468, The World Bank, Washington DC

Willig R (1976) Consumer's surplus without apology. Am Econ Rev 66:589-597 